\title{
Analysis of Using a Heliostat with Non-rotating Solar Energy Receivers
}

\author{
Vitaly Yanpavlis (Student, Riga Technical University), Alexander Suzdalenko (Researcher, Riga Technical \\ University), Andrew Stepanov (Docent, Riga Technical University), \\ Laura Dzelzkaleja (Scientific assistant, Riga Technical University)
}

\begin{abstract}
The use of solar energy in Northern countries is not as obviously reasonable as in countries that are located closer to the Equator due to bigger differences of daytime during changes of seasons, as well as lower solar irradiance. This paper investigates the advantages of using a heliostat with non-rotating solar energy receivers (like water/air heating collectors, stationary PV panels or solar illumination collectors). The optimal orientation of the solar receiver and the heliostat is discussed in detail for two different optimization strategies maximal energy and maximal operation period with irradiance higher than $400 \mathrm{~W} / \mathrm{m}^{2}$. The results of the analysis demonstrate that the heliostat allows prolonging the operation of solar receivers for $20 \%$ of time during the year, or allows extracting $30 \%$ more energy per annum if proper orientation angles are selected.
\end{abstract}

Keywords - renewable energy sources, solar energy, optimization

\section{INTRODUCTION}

The World's demand for electrical energy increases at a rate of $2.4 \%$ annually [1], meaning that new electrical plants should be installed on a regular basis. Due to people's awareness of climate change, the renewable energy sources become popular among end-users of electrical energy, and at the same time, governments finance various supporting programs to promote the usage of solar, wind, and other renewable energy sources [2].

The use of solar energy receivers (water heating collectors, air heating collectors, PV panels) is obviously reasonable in Southern countries due to the high intensity of solar irradiance and small changes of daytime during different seasons. Contrary, in Northern countries, where the changes of seasons influence the differences between daytime - the shortest day on 23 December and the longest day on 23 June (see fig. 1.), as a result, the usage of solar receivers at higher geographical latitudes limits their operation during winter period. Moreover, despite the fact that summer days are longer in regions that are closer to the poles, stationary solar receivers utilize solar power only when the Sun is located "above" the surface of the solar receiver, when direct sunlight is targeted to it. It is worth mentioning that the energy of the Sun is not utilized during morning and evening periods, when the Sun is located "behind" the solar receiver.

The figure 1 demonstrates the changes in daytime according to geographical latitude, while the practical limit of operation period for solar receiver during summer days is 12 hours.

Thus, the heliostat would allow using solar energy sinks for a longer period of time due to redirecting Sun rays to the target throughout the daytime. This paper investigates the best altitude angles of the solar receiver and the position of the heliostat that are optimal for maximizing the amount of received energy, or for a maximal period of time when it receives a minimum amount of solar energy.

The paper is organized in the following way: the second section discusses the application of the heliostat with different types of solar receivers; the third section provides mathematical equations describing the position of the Sun and irrdiance; the fourth section is dedicated to the analysis of the optimal position of the solar receiver and the heliostat; conclusions are made at the end of this article.

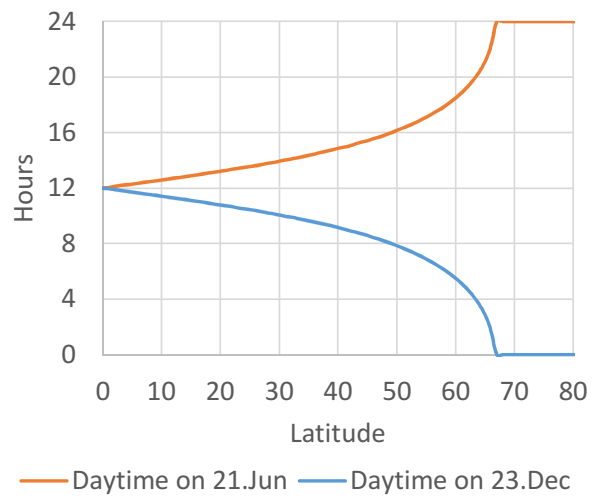

Fig. 1. Longest and shortest daytime accordingly to latitude.

\section{ADVANTAGES AND DISADVANTAGES OF A HELIOSTAT SYSTEM}

A heliostat redirects solar irradiance towards the target, but it should be noted that the effective surface of the heliostat changes during the day. As the heliostat is following the bisector line of the sunlight angle, the effective surface changes according to the cosine of the angle between the heliostat's normal vector and target direction, meaning that the effective reflecting surface is varying. The application of a stationary PV panel and a heliostat is questionable, as a negative effect can occur. When the PV panel is illuminated non-uniformly, a partial shading effect could happen that can decrease output power [3]. However, if the dimensions of the heliostat mirror are properly selected, it is possible to avoid the partial shading effect.

The use of additional solar energy with water or air heating collectors has no negative effect if the solar receiver is 
partially illuminated, as all the received energy is accumulated in heat.

In this context, when additional energy is redirected from the heliostat, it creates the problem of optimal altitude selection for solar energy receivers in order to maximize reception of energy throughout the year, or maximize the period of operation with minimal reception of solar energy.

\section{MODELLING OF SUN POSITION AND IRRADIANCE}

Solar irradiance is calculated based on empirical formula (1):

$$
I_{D}=1.353 \cdot 0.7^{A M^{0.678}}[\mathrm{~W} / \mathrm{h}],
$$

where AM (Atmospheric Mass) is the sunlight path at different Sun angles. The AM is calculated by the formula (2) that takes into account the non-perfection of the Earth's sphere:

$$
A M=\frac{1}{\cos \Theta+0.50572 \cdot(98.07995-\Theta)^{-1.6364}} .
$$

The theta angle depends on the daytime and the season, or in other words, on Earth's position in respect to the Sun, which is well described by astronomical algorithms in [4], while a simplified version is also available from online [5]. The main idea is to calculate the elevation angle and the azimuth of the Sun, then calculate the angle of the Sun in respect to normal vector of the solar receiver, so that the cosine of that angle will show the ratio of the received solar irradiance.

\section{ANALYSIS AND RESULTS}

In order to find the optimal position for solar energy receivers, a special program was developed in LabVIEW. The program calculates the position of the Sun and irradiance by entering date and time values. It also takes into account the altitude of the receiver and the heliostat's position to calculate the total solar power that is received.

The first analysis was done to find the optimal orientation of a solar energy receiver without the heliostat for Riga. The graphical representation of the yearly received solar power depending on the collector's orientation is presented in the figure 2 .

It can be seen from Figure 2 that the optimal receiver's azimuth (North $=0^{\circ}$ ) and altitude (horizon $=0^{\circ}$ ) angles are $178^{\circ}$ and $43^{\circ}$, correspondingly. The figure 3 represents hourly received power for all months, when optimal orientation is selected for the receiver.

The use of the heliostat provides additional power for the solar receiver that varies due to the Sun's movement. If the heliostat is located on the South side in respect to the receiver, the heliostat has almost $100 \%$ of efficiency, while at noon the efficiency drops to $40 \%$ due to higher sunlight falling angles.

Thus, it is obvious that the use of the heliostat may change the optimal orientation of the solar receiver. The target altitude for the heliostat should also be considered.

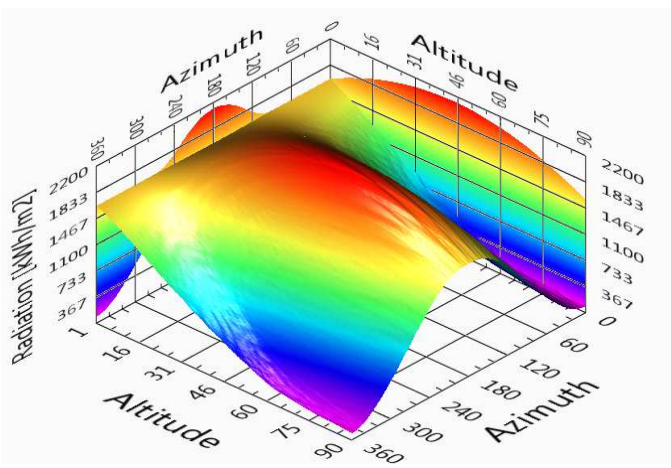

Fig. 2. Yearly received radiation at different orientation angles.

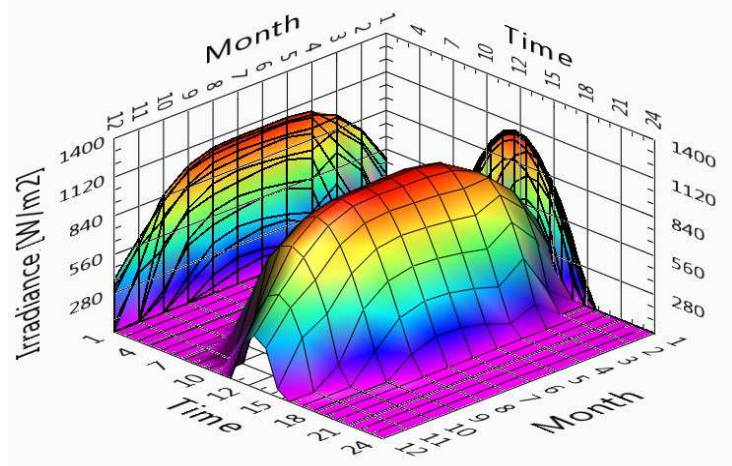

Fig. 3. Hourly irradiance at solar receiver.

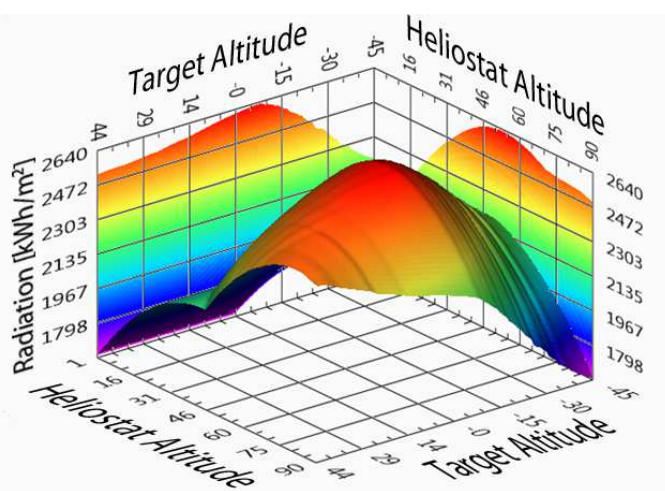

Fig. 4. Yearly received radiation at different altitudes of the receiver and the heliostat's target angle.

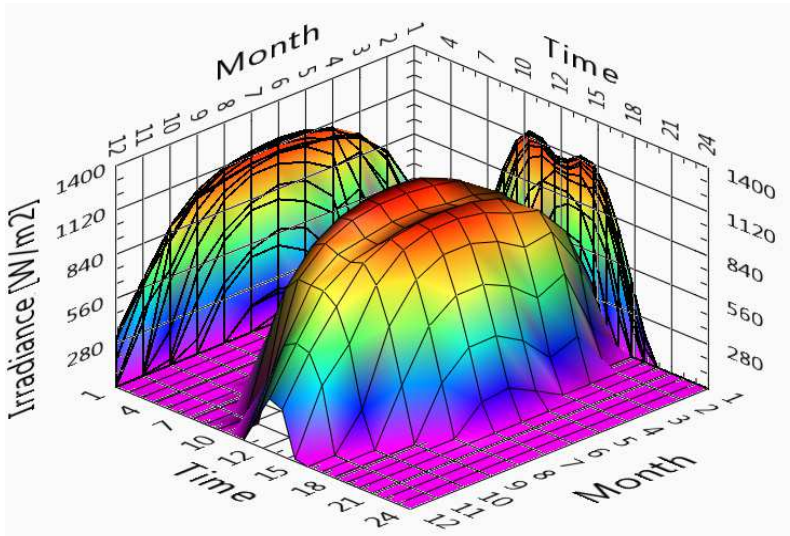

Fig. 5. Total hourly irradiance on the solar receiver when heliostat is used. 
The figure 4 demonstrates the total yearly received power for the solar receiver, when the heliostat is in use. The optimal altitude for the receiver is $51^{\circ}$, but the target orientation of the heliostat is $-8^{\circ}$, meaning that the heliostat should be located slightly below the receiver.

The figure 5 demonstrates the irradiance for an optimally oriented receiver and heliostat.

The figure 6 compares total hourly irradiance on the receiver in June with and without the heliostat.

The heliostat increases irradiance by $35 \%$ in comparison with only having a solar receiver. It should also be noted that the received energy graph has two maximal points during the day that approximately corresponds with the daily hot water consumption pattern for regular households. Consequently, the need for a large hot water reservoir could be considered.

The pattern of the daily received energy can also be modified by changing the azimuth orientation of the heliostat. The figure below demonstrates the orientation of the heliostat at $0^{\circ}, 30^{\circ}$ and $-30^{\circ}$ azimuth in respect to the receiver (see fig. 7.).

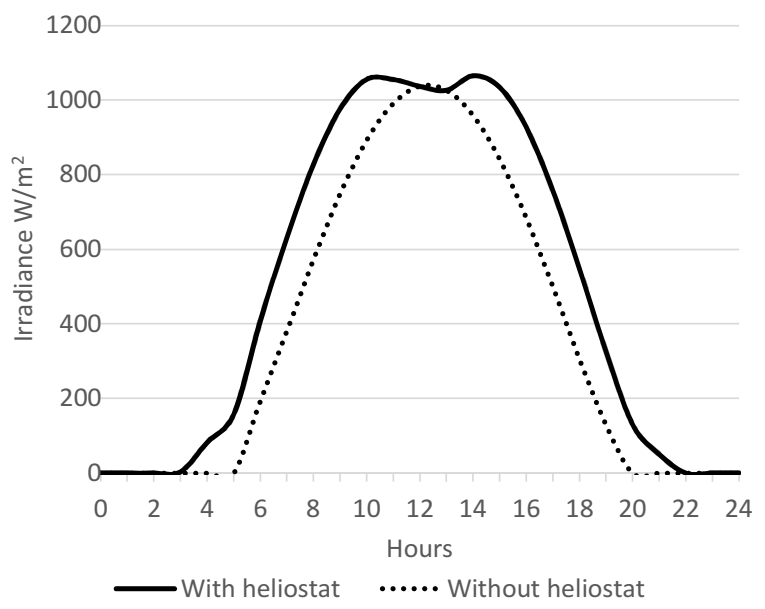

Fig. 6. Comparison of solar irradiance patterns at solar receiver with and without using heliostat.

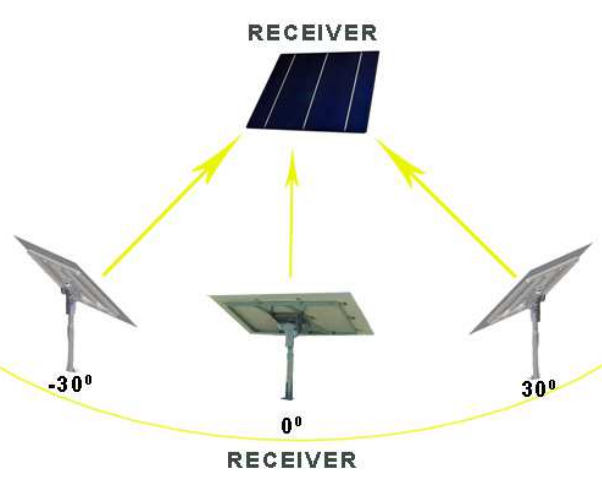

Fig. 7. Preview of different target angles $\left(0^{\circ}\right.$ corresponds to North).

The resulting pattern of solar irradiance on the solar receiver is demonstrated in the figure 8 . It is clearly visible that it is possible to shift the maximal irradiance (consequently, useful energy production) by changing the orientation of the heliostat. This feature could be utilized in applications where the consumption pattern has a particular maximum in morning or evening hours, so that the consumption pattern can be matched with the energy production pattern.

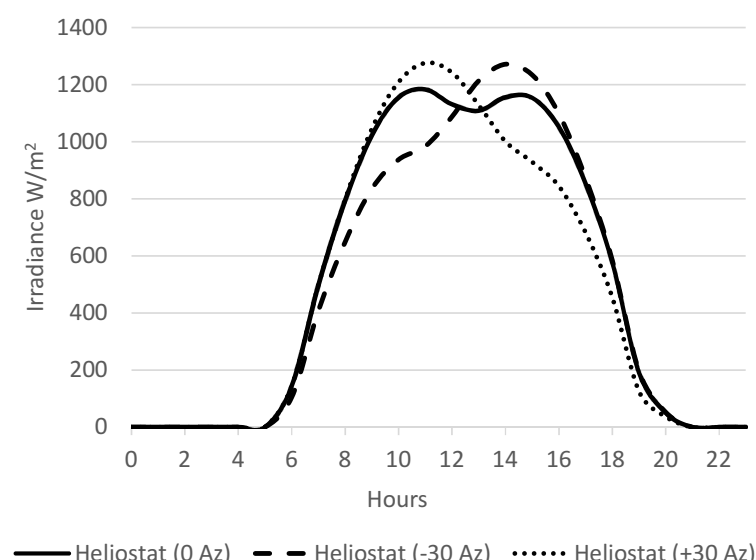

Fig. 8. Comparison of solar irradiance patterns at different positions of the heliostat.

Table I presents comparison data of yearly received energy of the solar receiver with/without the heliostat that is optimally oriented for receiving maximal energy or to have a maximal operation time period. Three cities were selected for this analysis: Madrid as a southern city, Riga as a northern city and Murmansk as a city above the polar circle.

TABLE I

COMPARISON OF YEARLY AMOUNT OF RADIATION AND OPERATION PERIOD

\begin{tabular}{|c|c|c|c|c|c|c|c|}
\hline \multirow[b]{2}{*}{ City } & \multirow[b]{2}{*}{ Optim. } & \multicolumn{2}{|c|}{ Receiver } & \multicolumn{2}{|c|}{ Heliostat } & \multirow{2}{*}{$\begin{array}{l}\mathrm{kWh} \\
/ \mathrm{m}^{2} \\
\text { /year }\end{array}$} & \multirow{2}{*}{$\begin{array}{l}\mathrm{h} / \text { year } \\
(>400 \\
\left.\mathrm{W} / \mathrm{m}^{2}\right)\end{array}$} \\
\hline & & Alt. & Az. & Alt. & Az. & & \\
\hline \multirow{4}{*}{$\begin{array}{l}\text { Madrid } \\
(40.25, \\
-3.42)\end{array}$} & $\begin{array}{l}\text { Max } \\
\text { Energy }\end{array}$ & 3 & 165 & - & - & 2825 & 3269 \\
\hline & $\begin{array}{l}\text { Max } \\
\text { Period }\end{array}$ & 6 & 105 & - & - & 2815 & 3348 \\
\hline & $\begin{array}{l}\text { Max } \\
\text { Energy }\end{array}$ & 22 & 168 & -30 & -9 & 3687 & 3250 \\
\hline & $\begin{array}{l}\text { Max } \\
\text { Period }\end{array}$ & 50 & 175 & 0 & -23 & 3394 & 3599 \\
\hline \multirow{4}{*}{$\begin{array}{l}\text { Riga } \\
(56.95, \\
24.12)\end{array}$} & $\begin{array}{l}\text { Max } \\
\text { Energy }\end{array}$ & 43 & 178 & - & - & 2116 & 2524 \\
\hline & $\begin{array}{l}\text { Max } \\
\text { Period }\end{array}$ & 53 & 185 & - & - & 2085 & 2575 \\
\hline & $\begin{array}{l}\text { Max } \\
\text { Energy }\end{array}$ & 51 & 178 & -8 & 0 & 2631 & 2934 \\
\hline & $\begin{array}{l}\text { Max } \\
\text { Period }\end{array}$ & 69 & 185 & 15 & 9 & 2565 & 3033 \\
\hline \multirow{4}{*}{$\begin{array}{l}\text { Murmansk } \\
(68.59 \text {, } \\
33.08)\end{array}$} & $\begin{array}{l}\text { Max } \\
\text { Energy }\end{array}$ & 45 & 175 & - & - & 1637 & 1988 \\
\hline & $\begin{array}{l}\text { Max } \\
\text { Period }\end{array}$ & 52 & 174 & - & - & 1624 & 2004 \\
\hline & $\begin{array}{l}\text { Max } \\
\text { Energy }\end{array}$ & 58 & 164 & -2 & -40 & 2098 & 2324 \\
\hline & $\begin{array}{l}\text { Max } \\
\text { Period }\end{array}$ & 61 & 165 & 7 & -29 & 2094 & 2347 \\
\hline
\end{tabular}




\section{V.CONCLUSIONS}

The heliostat redirects solar irradiance towards solar receiver and changes the pattern of the daily received energy. Some previously discussed doubts were confirmed-not all solar receivers can be easily used with a heliostat, as, for example, partial shading of a PV panel can occur if the dimensions of the heliostat are not properly selected. Nevertheless, the heating collectors are more appropriate for use with the heliostat.

The utilization of the heliostat in household application can increase the annually received energy by $20-30 \%$ or prolong the operation time period of the solar receiver by $10-20 \%-$ proper orientation angles for the solar receiver and position of the heliostat should be selected. The target orientation of the heliostat shifts the peak of solar irradiance that can be used to match the consumption pattern in some applications. As a result, in the case of heating collectors, the volume of the heat storage reservoir can be minimized.

\section{REFERENCES}

[1] F. Birol, "Power to the people," IAEA Bull., vol. 46, no. June, pp. 9-12, 2004.

[2] A. McCrone, "Global Trends in Renewable Energy Investment 2012," 2012.

[3] B. A. Alsayid, S. Y. Alsadi, J. S. Jallad, and M. H. Dradi, "Partial Shading of PV System Simulation with Experimental Results," Smart Grid Renew. Energy, vol. 04, no. 06, pp. 429-435, 2013.

[4] J. Meeus, Astronomical Algorithms, 1st ed. Willmann-Bell, 1991, p. 429.

[5] J. Giesen, "Basics of Positional Astronomy," 2012. [Online]. Available: http://www.geoastro.de/elevaz/basics/. [Accessed: 21-Jul-2014].
V. Yanpavlis received B.Sc (20013), M.Sc. (2014) grades in Riga Technical University in the field of electrical engineering. His research interests are related with renewable energy sources, energy efficient illumination technologies and design of control system based on microcontrollers. He has designed the program in LabVIEW that calculates yearly solar radiation with or without the use of heliostat for any geographical coordinates. This program allows choosing optimal angles for heliostat and solar receiver.

e-mail: v.janpavlis@gmail.com

A. Suzdalenko received B.Sc (2007), M.Sc. (2009) and Dr.sc.ing. (2013) grades in Riga Technical University in the field of electrical engineering. His research interests are related to design and control of power electronics converters. He contributed to intelligent household energy systems, studying the power balancing approaches, non-intrusive load monitoring algorithms and advantages of usage of LEDs.

He has practical experience, working for two years in scientific and production association ELLAT Ltd as electronic device engineer.

$\mathrm{He}$ is IEEE member since 2010 and joins PELS, IES and IAS societies. e-mail: Aleksandrs.Suzdalenko@RTU.lv

A. Stepanov has received B.Sc. and M.Sc. in Riga Technical University (in 2004 and 2006 respectively). The master thesis was focused on research and development of uninterruptible power supplies containing specific energy storages - supercapacitors. He has completed doctoral studies in 2010 and at present time he is employed at Riga Technical University, Department of Power Electronics and Electrical Technologies as a senior researcher. His research interests are related to uninterruptible power supplies, alternative energy sources (solar and wind) and new technologies of storing electrical energy.

Andrew Stepanov is an IEEE member for 7 years

e-mail: Andejs.Stepanovs@RTU.lv

L. Dzelzkaleja received B.Sc and M.Sc. in Environmental science from Riga Technical University, Riga, Latvia in 2009 and 2012, respectively. Since 2013 she is employed by Riga Technical University Cesis branch. Current positions are scientific assistant and lecturer. Research interests include environmental policy and energetics.

e-mail: laura.dzelzkaleja_1@rtu.lv 